\title{
Editorial from the Editor in Chief
}

The journal of Laser and Particle Beams wants to take this opportunity to congratulate Dr. Max Tabak and Dr. Joseph D. Kilkenny on the occasion of being selected by the American Nuclear Society as winners of the 2005 Edward Teller award. Both scientists were recognized for their pioneering work in the field of fusion research. Nuclear fusion and especially inertial confinement fusion constitutes a specific field of interest which is frequently discussed in this Journal. Both scientists have previously contributed to this journal, and we are very proud that our recent December 2005 issue carried an article by Kilkenny et al. (2005), related to this topic. The same issue carries articles by two former Teller Award winners (Hora, 2005; Miley et al., 2005).

Last year saw a major change in the Editorial Board of our journal, accompanied by a change in publication policy. Laser and Particle Beams does no longer publish conference proceedings. However, at conferences that cover topics of specific interest to the readers and authors of Laser and Particle Beams, we encourage scientists to submit original papers to our journal. This was the case with the European Conference on Laser Interaction with Matter (XXVIII ECLIM, Rome, Caruso et al., 2005) and the workshop on Fast High Density Plasma Blocks Driven by Picosecond Terawatt Lasers, held in Sydney (Osman, 2005). Due to the fact that authors met during these events and discussed their results, an outstanding number of references during the first year already were acquired. Therefore the chances for a Laser and Particle Beams article to be recognized already in the first year have risen considerably. Among those cited most were Roth et al. (2005), Kong et al. (2005), Neumayer et al. (2005), and Deutsch et al. (2005).

During the coming year we will cover the Second International Conference on the Frontiers of Plasma Physics and Technology (Desai \& Pant, 2006).

The year 2006 will see Laser and Particle Beams being ranked among the top journals in applied physics. The editorial board will therefore continue the current publication policy, and ask readers as well as authors of Laser and Particle Beams to suggest further improvements.

Last year Dr. M. Kanapathipillai, who had just finished his $\mathrm{PhD}$ degree and started on his professional career, also contributing as author to Laser and Particle Beams
(Khaydarov et al., 2005), died unexpectedly while he was still finishing a new article (Kanapathipillai, 2006). His friends and colleagues will keep his memory alive. The editor is especially grateful to his colleagues who finished the article and answered the questions of the reviewers.

The editor on behalf of the editorial board expresses the hope that all readers and authors will enjoy the new volume, and we wish you continued success in the year 2006.

\section{REFERENCES}

Caruso, A., Eliezer, S., Strangio, C. (2005). Guest Editors' Preface: XXVIII ECLIM Rome. Laser Part. Beams 23, 3.

Desai, T. \& Pant, H.C. (2006). Guest Editor's Preface: Second International Conference on the Frontiers of Plasma physics and Technology. Laser Part. Beams 24, \#06-001.

Deutsch, C., Bret, A. \& Fromy, P. (2005). Mitigation of electromagnetic instabilities in fast ignition scenario. Laser Part. Beams 23, 5-8.

Hora, H. (2005). Difference between relativistic petawatt-picosecond laser-plasma interaction and subrelativistic plasma-block generation. Laser Part. Beams 23, 441-451.

Kanapathipillai, M. (2006). Nonlinear absorption of ultra short laser pulses by clusters. Laser Part. Beams 24, \#06-003.

Khaydarov, R.T., Berdiyorov, G.R., Kunishev, U., Khalmuratov, M., Tojikhonov, E. \& Kanapathipillai, M. (2005). Investigation of PbMg target characteristics by a laser mass-spectrometer. Laser Part. Beams 23, 521-526.

Kilkenny, J.D., Alexander, N.B., Nikroo, A., Steinman, D.A., Nobile, A., Bernat, T., Cook, R., Letts, S., Takagi, M. \& Harding, D. (2005). Laser targets compensate for limitations in inertial confinement fusion drivers. Laser Part. Beams 23, 475-482.

Kong, H/J., LeE, S.K. \& LeE, D.W. (2005). Beam combined laser fusion driver with high power and high repetition rate using stimulated Brillouin scattering phase conjugation mirrors and self-phase-locking. Laser Part. Beams 23, 55-59.

Miley, G.H., Hora, H., Osman, F., Evans, P. \& Toups, P. (2005). Single event laser fusion using ns-MJ laser pulses. Laser Part. Beams 23, 453-460.

Neumayer, P., Bock, R., Borneis, S., Brambrink, E., Brand, H., Caird, J., Campbell, E.M., Gaul, E., Goette, S., Haefner, C., Hahn, T., Heuck, H.M., Hoffmann, DH.H., Javorkova, D., Kluge, H.J., Kuehl, T., Kunzer, S., Merz, T., Onkels, E., Perry, M.D., Reemts, D., Roth, M., SameK, S., Schaumann, G., Schrader, F., Seelig, W., Tauschwitz, 
A., Thiel, R., Ursescu, D., Wiewior, P., Wittrock, U. \& Zielbauer, B. (2005). Status of PHELIX laser and first experiments. Laser Part. Beams 23, 385-389.

Osman, F. (2005).Guest Editor's Preface: Workshop on Fast High Density Plasma Blocks Driven By Picosecond Terawatt Lasers. Laser Part. Beams 23, 399-400.

Roth, M., Brambrink, E., Audebert, P., Blazevic, A., Clarke, R., Cobble, J., Cowan, T.E., Fernandez, J., Fuchs, J.,
Geissel, M., Habs, D., Hegelich, M., KaRsch, S., Ledingham, K., Neely, D., Ruhl, H., Schlegel, T. \& Schreiber, J. (2005). Laser accelerated ions and electron transport in ultraintense laser matter interaction. Laser Part. Beams 23, 95-100.

Dieter H.H. Hoffmann Editor in Chief 